\title{
Remission of arthritis and radiological improvement after combination therapy for non-Hodgkin's lymphoma in a patient with rheumatoid arthritis undergoing treatment with D-penicillamine
}

\author{
P SHELDON AND J K WOOD
}

From the Departments of Rheumatology, and Haematology, Leicester Royal Infirmary, Leicester

SUMMARY A patient receiving D-penicillamine for rheumatoid arthritis developed a lymphoma, therapy for which resulted not only in haematological resolution but marked remission of $\stackrel{c}{\stackrel{c}{\rho}}$ rheumatoid disease activity, including radiological improvement.

A 51-year-old furnace engineer presented with a three-year history of polyarthritis, which had made him give up work eight months previously. Examination revealed large rheumatoid nodules over both elbows, swollen extensor sheaths over the wrists, swollen metacarpophalangeal joints, and flexor deficits of the finger joints.

Investigations revealed a positive rheumatoid factor, latex titre $1: 160$, low titre antinuclear factor $1: 64$ (IgG class), plasma viscosity $1.86 \mathrm{cp}$ (normal $1.50-1.72 \mathrm{cp}$ ), total white cell count $4.6 \times 10^{9} / 1$.

$X$-rays showed erosions of the heads of the second left and second and third right metacarpophalangeal joints (Figs. 1a and 2a).

He was taking $7.2 \mathrm{~g}$ daily of salicylates (having found more recently developed non-steroidal antiinflammatory agents no better), and was therefore started on D-penicillamine $250 \mathrm{mg}$ daily. The dose was doubled after six weeks, increased to $625 \mathrm{mg}$ daily three months later, then $750 \mathrm{mg}$ daily six months after commencement. At this stage proteinuria occurred, $1.5 \mathrm{~g}$ being excreted in $24 \mathrm{~h}$. No drug adjustment was made and it disappeared within two months. Simultaneously leucopenia $\left(3 \cdot 1 \times 10^{9} / 1\right)$ was noted, and the differential white cell count was normal, no immature forms being present.

Accepted for publication 10 September 1984.

Correspondence to Dr P. Sheldon, Department of Microbiology, University of Leicester, University Road, Leicester LE1 7RH.
The count rose to normal within two monthso without any alteration in dose. He improved con- 0 siderably, the mean plasma viscosity falling from $\stackrel{\AA}{\AA}$ 1.93 to $1.7 \mathrm{cp}$. Subjectively there was reduction in $\overrightarrow{\overrightarrow{0}}$ early morning stiffness from $2 \mathrm{~h}$ to $1 \mathrm{~h}$, and his 3 nodules became smaller.

Twenty-six months after beginning D-penicillamine, he developed an enlarging painless swellingu round the left clavicle.

Examination showed a non-tender $5 \mathrm{~cm}$ diameter hard round mass arising over the medial third of the clavicle. There was no lymphadenopathy, hepatosplenomegaly, or bruising. The mass was excised under general anaesthesia. Histology showed $a^{\circ}$ lymphoblastic lymphoma (undesignated). ${ }^{1} A_{0}^{D}$ trephine bone marrow examination showed focal areas of lymphocytes, considered to be consistent with lymphomatous infiltration. Other investiga- $N$ tions included normal chest and pelvic $x$-rays, the lumbar spine showed spondylosis only, and CT $\operatorname{scan}^{\omega}$ of the abdomen was normal. Peripheral blood lymphocytes did not show a $B$ cell clone, but $\mathrm{T}$ cello numbers were slightly reduced, $48 \%$ forming sheeps cell rosettes (control 62\%). Serum protein electrophoresis showed no evidence of paraprotein or immunosuppression. The D-penicillamine was, stopped.

He received combination therapy with cyclophos- $\frac{D}{2}$ phamide, vincristine, adriamycin, and prednisolone? 


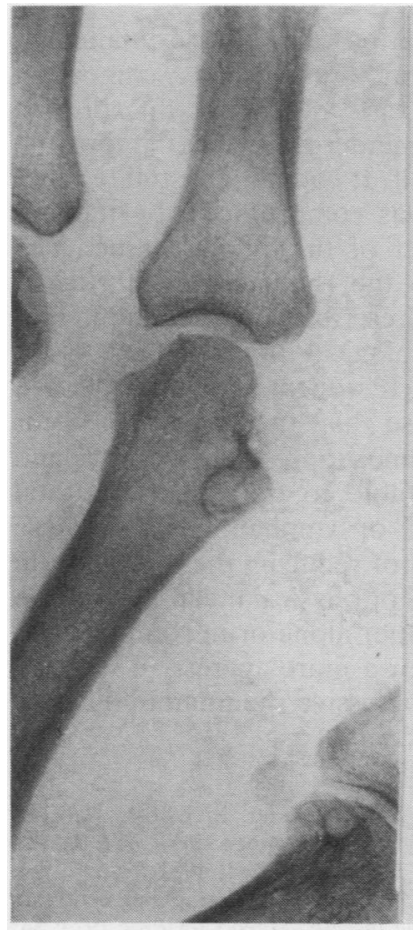

Fig. 1a

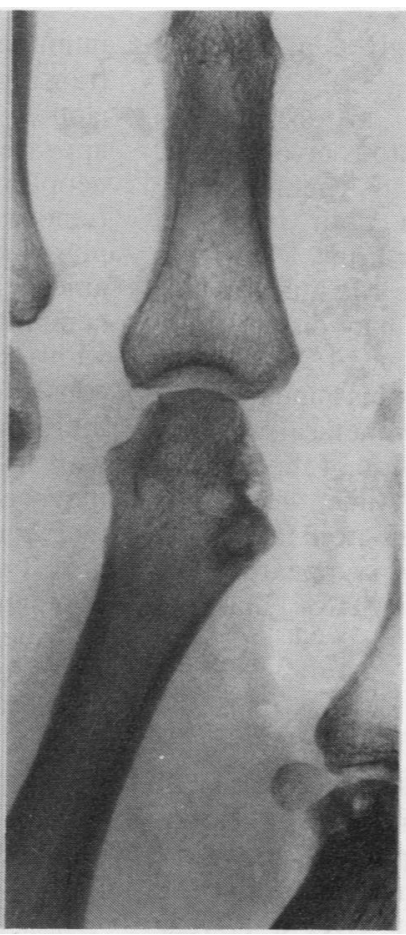

Fig. 1b

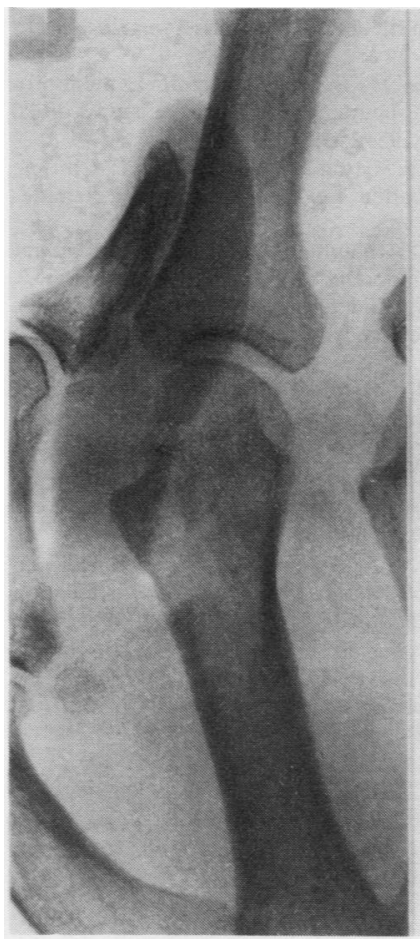

Fig. 2a

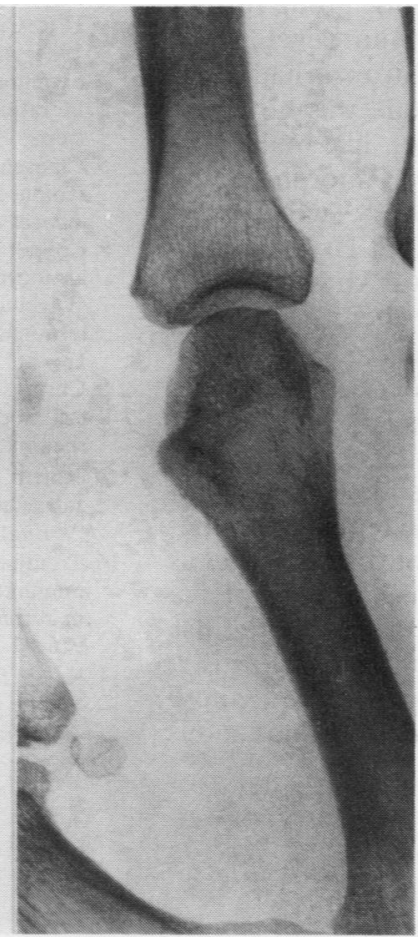

Fig. 2b
Fig. 1 (a) $X$-ray of second left metacarpophalangeal joint on 26 June 1979. (b) The same joint on 10 October 1984.

Fig. 2 (a) $X$-ray of second right metacarpophalangeal joint on 26 June 1979. (b) The same joint on 10 October 1984. 
Six courses of treatment were given at monthly intervals.

Repeat marrow examination at six months showed no evidence of lymphomatous involvement. Six months after discontinuation of chemotherapy he was in complete remission both from the lymphoma and the rheumatoid arthritis. There was no morning stiffness, no soft tissue swelling or flexor deficit, and the elbow nodules had disappeared. Rheumatoid factor (latex) was only 1:20. He was receiving no medication. $X$-rays of his hands showed evidence of recortication of the metacarpal head erosions (Figs $1 b$ and $2 b$ ). Remission of the arthritis lasted for 16 months, at which time the plasma viscosity was $1.78 \mathrm{cp}$, and the rheumatoid factor titre $1: 20$. Symptoms then gradually reappeared, the rheumatoid factor titre rose to $1: 160$ and has remained so for six months.

\section{Discussion}

Various reports of neoplastic disease occurring in patients with rheumatoid arthritis have appeared. Eight cases of large-celled lymphoma among 19 cases of neoplasia were found in one study. ${ }^{2}$ A consecutive series of 489 patients over a 17-year period in Birmingham revealed 36 cancers, including six cases of lymphoma. ${ }^{3}$ The same group further reported a series of 20 patients who developed a lymphoproliferative disorder. Thirteen had nonHodgkin's lymphoma, of whom one was histologically diagnosed as lymphoblastic, like our case. Twelve of these were thought on morphological grounds to have arisen from B cells. Two cases of chronic lymphocytic leukaemia (CLL) were also found. ${ }^{4}$ Only one of these cases was known to have received $\mathrm{D}$-penicillamine, though there has been a separate report of CLL which occurred in a female with rheumatoid arthritis who underwent treatment with D-penicillamine for five years. ${ }^{5}$ It does not seem very likely from these accounts that previous therapy was of relevance in the development of these malignancies which affect the reticuloendothelial system and may involve cells of the histiocyte as well as the B series. Malignant histiocytosis of the intestine, a tumour derived from the histiocyte, has occurred in a patient with rheumatoid arthritis. ${ }^{6}$

The cause of the association between these diseases remains open to conjecture. Continuous

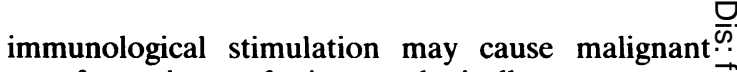
transformation of immunologically competent $\overrightarrow{\vec{F}}$ clones, ${ }^{7}$ but in the case described the disease $-{ }^{7}$ appeared to be coming under control at the time the $\frac{\bar{C}}{\circ}$ neoplasm declared itself. It could be postulated that $\overline{\bar{c}}$ tumour surveillance was compromised by the im- $\widehat{\Phi}$ munomodulatory effect of the penicillamine. The ameliorating effect on the rheumatoid arthritis of ${ }^{\text {(s) }}$ combination therapy prescribed for the lymphoma, $\overrightarrow{0}$ with subsequent radiological improvement is of $\overrightarrow{-}$ considerable interest. It appears to have been $\mathrm{a}_{\bar{\sigma}}$ more dramatic response than that known to occuro with single drug 'immunosuppressive' therapy ${ }^{8}$ and $\overline{0}$ may be more comparable to the effects of total $f$ lymphoid irradiation ${ }^{10}$ or lymphapheresis. ${ }^{11}$ These ${ }^{\circ}$ are all potent methods of reducing the immunocyte population by chemical or physical means. It may be

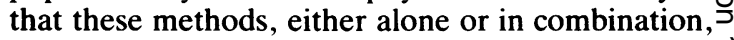
could form the basis for a more aggressive strategy in selected cases of progressive rheumatoid disease.

\section{References}

1 Stuart A E, Stanfield A G, Lauder I. British National $\infty$ Lymphoma classification. In: Lymphomas other than Hodgkin's. disease. Oxford: Oxford University Press, 1981.

2 Banks P M, Witrak G A, Conn D L. Lymphoid neoplasia following connective tissue disease. Mayo Clin Proc 1979; 54:
104-8.

3 Prior P, Symmons D P M, Hawkins C F, Scott D L, Brown D R. Cancer morbidity in rheumatoid arthritis. Ann Rheum Dis 1984; 43: 128-31.

4 Symmons D P M, Ahern M, Bacon P A, et al. Lymphopro- $\overrightarrow{\bar{O}}$ liferative malignancy in rheumatoid arthritis: a study of 203 cases. Ann Rheum Dis 1984; 43: 132-5.

5 Clausen J E, Arndal J C K, Gram L, Kudah S, Fog P. Chronic lymphocytic leukaemia after treatment with penicillamine. Lancet 1978; ii: 152.

6 Cooper C, Cawley M I D. Rheumatoid arthritis and malignant $\overline{\mathrm{C}}$ histiocytosis of the intestine. Ann Rheum Dis 1984; 43: 766-7.

7 Wegelius O, Skrifvars B, Andersson L. Rheumatoid arthritis terminating in plasmatocytoma. Acta Med Scand 1970; 187: ̊̊ 133-8.

8 Currey H L F, Harris J, Mason R M, et al. Comparison of azathioprine, cyclophosphamide, and gold in treatment of음 rheumatoid arthritis. $B r$ Med $J$ 1974; iii: 763-6.

9 Kotzin B L, Strober S, Engleman E G, et al. Treatment of intractable rheumatoid arthritis with total lymphoid irradiation. N Engl J Med 1981; 305: 969-76.

10 Trentham D E, Belli J A, Anderson R J, et al. Clinical and immunologic effects of fractionated total lymphoid irradiation in refractory rheumatoid arthritis. $N$ Engl J Med 1981; 305: N 976-82.

11 Karsh J, Klippel J H, Plotz P H, Decker J L, Wright D G, Wayne Flye $M$. Lymphapheresis in rheumatoid arthritis. Arthritis Rheum 1981; 24: 867-73. 